\title{
Reaction of Functionalized Anilines with Dimethyl Carbonate over NaY Faujasite. 3. Chemoselectivity toward Mono-N-methylation
}

\author{
Maurizio Selva,* Pietro Tundo, and Alvise Perosa \\ Dipartimento di Scienze Ambientali del 'U niversità Ca' Foscari, \\ Calle Larga S. Marta 2137, 30123-Venezia, I taly \\ selva@univeit
}

Received April 29, 2003

\begin{abstract}
In the presence of $\mathrm{NaY}$ faujasite, dimethyl carbonate $\left(\mathrm{MeOCO}{ }_{2} \mathrm{Me}, \mathrm{DMC}\right)$ is a highly chemoselective methylating agent of functionalized anilines such as aminophenols (1), aminobenzyl alcohols (2), aminobenzoic acids (3), and aminobenzamides (4). The reaction proceeds with the exclusive formation of $\mathrm{N}$-methylanilines without any concurrent $\mathrm{O}$-methylation or $\mathrm{N}$-/O-methoxy carbonylation side processes. Particularly, only mono- $\mathrm{N}$-methyl derivatives $\left[\mathrm{XC}_{6} \mathrm{H}_{4} \mathrm{NHMe}, \mathrm{X}=\mathrm{o}-, \mathrm{m}-\right.$, and $\mathrm{p}-\mathrm{OH}$; o- and $\mathrm{p}-\mathrm{CH}_{2} \mathrm{OH}$; o- and $\mathrm{p}-\mathrm{CO}_{2} \mathrm{H}$; o- and $\mathrm{p}-\mathrm{CONH}_{2}$ ] are obtained with selectivity up to $99 \%$ and isolated yields of $74-99 \%$. DMC, which usually promotes methylations only at $\mathrm{T}>120^{\circ} \mathrm{C}$, is activated by the zeolite catalyst and it reacts with compounds $\mathbf{1}, \mathbf{2}$, and $\mathbf{4}$, at $90^{\circ} \mathrm{C}$. Aminobenzoic acids (3) require a higher reaction temperature $\left(\geq 130^{\circ} \mathrm{C}\right)$.
\end{abstract}

\section{Introduction}

The mono-N-methylation of primary aromatic amines is a key transformation in many organic syntheses. ${ }^{1}$ However, both direct and indirect alkylation methods are often problematic from synthetic and environmental standpoints: (i) the reaction selectivity suffers from competing bis- $\mathrm{N}$-alkylation side reactions, ${ }^{2}$ (ii) common methylating reagents (methyl halides and dimethyl sulfate) are toxic and dangerous, ${ }^{3}$ and (iii) multistep sequences (e.g., Eschweiler-Clarke-type reactions ${ }^{4}$ and reduction processes ${ }^{5}$ ) may require harsh conditions not compatible with labile functional groups or not readily available starting materials.

We have recently reported that in the presence of alkali-metal-exchanged Y-faujasites, a direct and highyield mono-N-methylation reaction of anilines can be performed with the use of both dimethyl and al kylmethyl carbonates $\left[\mathrm{ROCO} \mathrm{C}_{2} \mathrm{Me} ; \mathrm{R}=\mathrm{Me}, \mathrm{MeO}\left(\mathrm{CH}_{2}\right)_{2} \mathrm{O}\left(\mathrm{CH}_{2}\right)_{2}\right]$ as the alkylating agents. ${ }^{6}$ Accordingly, the corresponding $\mathrm{N}$-methylamines are prepared with an unprecedented

* Corresponding author. Fax: +390412348620.

(1) (a) March, J. In Advanced Organic Chemistry, $4^{\text {th }}$ Ed.; Wiley: New York, 1991. (b) Carruthers, W. In SomeModern Synthetic Methods of Organic Synthesis, 3rd ed.; Cambridge University Press: Cambridge, 1989.

(2) Gibson, M. S. In The Chemistry of the Amino Group; Patai, S., Ed.; Interscience Pub.: London 1968; Chapter 2, pp 45-62.

(3) (a) Ono, Y. PureAppl. Chem. 1996, 68, 367. (b) Selva, M.; Tundo, P. Acc. Chem Res. 2002, 35(9), 706-716.

(4) (a) Moore, M. L. Org. React. 1949, 5, 301. (b) Krishnamurthy, S. Tetrahedron Lett. 1982, 3315. (c) Uchiyama, M.; et al. J . Am. Chem. Soc. 1997, 119, 11425.

(5) (a) Katritzky, A. R.; Drewniak, M.; Aurrecoechea, J . M. J . Chem. Soc., Perkin Trans. 1, 1987, 2539. (b) Katritzky, A. R.; Rachwal, S. Rachwal, B. J . Chem. Soc., Perkin Trans. 1, 1987, 805. (c) Verardo, G.; Giumanini, A. G.; Strazzolini, P.; Poiana, M. Synthesis 1993, 121. (d) Feringa, B. L.; J ansen, J. F. G. A. Synthesis 1988, 184. (e) Kadin, S. B. J . Org. Chem. 1973, 38, 1348.

\section{SCHEME 1}

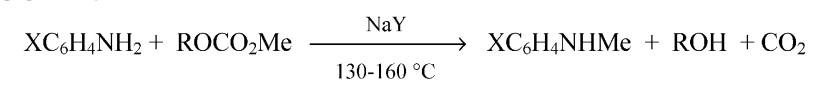

$\mathrm{R}=\mathrm{Me}, \mathrm{MeO}\left(\mathrm{CH}_{2}\right)_{2} \mathrm{O}\left(\mathrm{CH}_{2}\right)_{2} ; \mathrm{X}=\mathrm{H}, p-\mathrm{NC}, p-\mathrm{O}_{2} \mathrm{~N}, p-\mathrm{Cl}, o-\mathrm{MeO}_{2} \mathrm{C}, 2,6$-di-Me

selectivity of $90-97 \%$ at substantially quantitative conversions (Scheme 1 ).

Besides, the reaction is a truly environmentally friendly procedure: dialkyl carbonates, particularly dimethyl carbonate (DMC), are nontoxic compounds, which allow catalytic alkylation processes without the production of inorganic or organic wastes. $3,6,7$

In this paper, we report that the combined use of DMC and sodium-exchanged $\mathrm{Y}$-zeolite $(\mathrm{NaY})$ is a valuable protocol for the $\mathrm{N}$-methylation of functionalized anilines such as aminophenols (1), aminobenzyl alcohols (2), aminobenzoic acids (3), and aminobenzamides (4). In these cases, the reaction not only shows a very high mono-N-methyl selectivity (up to 99\%), but it proceeds with a complete chemoselectivity toward the amino group, the other functionalities $\left(\mathrm{OH}, \mathrm{CO}_{2} \mathrm{H}, \mathrm{CONH}_{2}\right)$ being fully preserved from alkylation and/or transesterification reactions.

\section{Results and Discussion}

Aminophenols (1). The direct alkylation, particularly methylation, of aminophenols with conventional methy-

(6) (a) Selva, M.; Bomben, A.; Tundo, P. J . Chem. Soc., Perkin Trans. 1 1997, 1041; (b) Selva, M.; Tundo, P.; Perosa, A. J . Org. Chem. 2001, 66, 677. (c) Selva, M.; Tundo, P.; Perosa, A. J . Org. Chem. 2002, 67, 9238-9247.

(7) (a) Romano, U.; Rivetti, F.; Di Muzio, N., 1979, US Pat. 4,318,862, 1981; Chem. Abstr. 80141; (b) Rivetti, F.; Romano, U.; Delledonne D. In Green chemistry: Designing Chemistry for the Environment; Anastas, P., Williamson, T. C., Eds.; ACS Symposium Series, Vol. 626, 1996; pp 70-80. The coproduct alcohol (ROH) can, in principle, be recycled to the production of the carbonate. 
TABLE 1. Reaction of Aminophenols $(1 a-c)$ with DMCa

\begin{tabular}{|c|c|c|c|c|c|c|c|c|c|}
\hline \multirow[b]{2}{*}{ entry } & \multirow[b]{2}{*}{ substrate } & \multirow[b]{2}{*}{ catalyst } & \multirow[b]{2}{*}{ cosolvent $(\mathrm{mL})$} & \multirow[b]{2}{*}{$\mathrm{T},{ }^{\circ} \mathrm{C}$} & \multirow[b]{2}{*}{$\mathrm{t}, \mathrm{h}$} & \multirow[b]{2}{*}{$\%$ conv } & \multicolumn{3}{|c|}{ products } \\
\hline & & & & & & & & $\%$, by GC & $\%$ yield $^{b}$ \\
\hline \multirow[t]{2}{*}{1} & 1a & $\mathrm{K}_{2} \mathrm{CO}_{3}$ & triglyme (35) & 135 & 5 & 2.5 & $\mathrm{p}-\mathrm{HOC}_{6} \mathrm{H}_{4} \mathrm{NHMe}$ & 1.7 & \\
\hline & & & & & & & $\mathrm{p}-\mathrm{MeOC}_{6} \mathrm{H}_{4} \mathrm{NH}_{2}$ & 0.7 & \\
\hline \multirow[t]{2}{*}{2} & la & $\mathrm{K}_{2} \mathrm{CO}_{3}$ & DME (35) & 150 & 5 & 2 & $\mathrm{p}-\mathrm{HOC}_{6} \mathrm{H}_{4} \mathrm{NHMe}$ & 0.7 & \\
\hline & & & & & & & $\mathrm{p}-\mathrm{MeOC}_{6} \mathrm{H}_{4} \mathrm{NH}_{2}$ & 0.8 & \\
\hline \multirow[t]{2}{*}{3} & la & $\mathrm{K}_{2} \mathrm{CO}_{3}$ & DMF (15) & 125 & 4 & 8 & $\begin{array}{l}\text { p-HOC }{ }_{6} \mathrm{H}_{4} \mathrm{NHM}^{-} \\
\mathrm{p}-\mathrm{MeOC}_{6} \mathrm{H}_{4} \mathrm{NH}_{2}\end{array}$ & $\begin{array}{l}5 \\
2\end{array}$ & \\
\hline & la & $\mathrm{K}_{2} \mathrm{CO}_{3}$ & DMF (15) & 125 & 19 & 77 & $\begin{array}{l}\text { p-MeOC }{ }_{6} \mathrm{H}_{4} \mathrm{NHMe} \\
\text { p-MeOC }{ }_{6} \mathrm{H}_{4} \mathrm{NH}_{2} \\
\text { p-MeOC }{ }_{6} \mathrm{H}_{4} \mathrm{NMe}_{2} \\
\text { p-MeOC }{ }_{6} \mathrm{H}_{4} \mathrm{NHCO}{ }_{2} \mathrm{Me} \\
\text { p-MeOC }{ }_{6} \mathrm{H}_{4} \mathrm{~N}(\mathrm{Me}) \mathrm{CO}_{2} \mathrm{Me}\end{array}$ & $\begin{array}{r}22 \\
23 \\
18 \\
6 \\
8\end{array}$ & \\
\hline 4 & la & $\mathrm{NaY}$ & triglyme (35) & 90 & 5 & 99 & $\mathrm{p}-\mathrm{HOC}_{6} \mathrm{H}_{4} \mathrm{NHMe}(\mathbf{5 a})$ & 99 & \\
\hline 5 & la & $\mathrm{NaY}$ & DME (35) & 86 & 7 & 100 & $\mathrm{p}-\mathrm{HOC}_{6} \mathrm{H}_{4} \mathrm{NHMe}(5 \mathrm{a})$ & 99 & 91 \\
\hline $6 a$ & $1 a$ & $\mathrm{NaY}$ & DMF (15) & 90 & 24 & $<1$ & $\mathrm{p}-\mathrm{HOC}_{6} \mathrm{H}_{4} \mathrm{NHMe}$, trace & & \\
\hline $6 \mathrm{~b}$ & la & $\mathrm{NaY}$ & MeCN (35) & 81 & 24 & $<1$ & $\mathrm{p}-\mathrm{HOC}_{6} \mathrm{H}_{4} \mathrm{NHMe}$, trace & & \\
\hline 7 & $\mathbf{1 b}$ & $\mathrm{NaY}$ & - & 90 & 3 & 100 & $\mathrm{O}-\mathrm{HOC}_{6} \mathrm{H}_{4} \mathrm{NHMe}(\mathbf{5 b})$ & 99 & 99 \\
\hline 8 & $\mathbf{1 b}$ & $\mathrm{p}-\mathrm{TsOH}$ & - & 130 & 4 & 35 & $\begin{array}{l}\mathrm{O}-\mathrm{HOC}_{6} \mathrm{H}_{4} \mathrm{NHMe} \\
\text { unidentified productc }\end{array}$ & $\begin{array}{l}15 \\
18\end{array}$ & \\
\hline 9 & 1c & $\mathrm{NaY}$ & - & 90 & 7 & 97 & $\mathrm{~m}-\mathrm{HOC}_{6} \mathrm{H}_{4} \mathrm{NHMe}(\mathbf{5 c})$ & 96 & 89 \\
\hline
\end{tabular}

a Reactions were carried out using a DMC/substrate molar ratio of 13 and of 39 for compounds $\mathbf{l a}$ and $\mathbf{1 b}, \mathbf{c}$, respectively. The $\mathbf{1}: \mathrm{NaY}$ weight ratio was of 1 . b I solated yield. c Unknown compound. Mass spectrum $\left(M^{+}, m / z=137\right)$ suggests the formation of a dimethyl derivative.

lating reagents is unsatisfactory: because of the ambident nucleophilicity of such compounds, both $\mathrm{N}, \mathrm{N}$ dimethyl and N,O-dimethyl byproducts form. ${ }^{8}$ Indirect procedures that involve reductive alkylations, ${ }^{4 b, 9}$ hydrolytic cleavage of benzoxazoles, ${ }^{10}$ and O-demethylation reactions ${ }^{11}$ are often preferred, even though sometimes $\mathrm{N}, \mathrm{N}$-dimethyl derivatives are still the major products. ${ }^{12}$

To test the applicability of DMC as an alternative methylating agent, p-aminophenol (1) was chosen as a model compound. Initial reactions were carried out at temperatures of $90-150{ }^{\circ} \mathrm{C}$ using solutions of $\mathbf{l a}(1.0 \mathrm{~g}$, $9.2 \mathrm{mmol}), \operatorname{DMC}(10 \mathrm{~mL}, 0.12 \mathrm{~mol})$, and a cosolvent (DMF, DME, triglyme, and $\mathrm{MeCN}^{13}$ ) in the presence of both $\mathrm{K}_{2} \mathrm{CO}_{3}$ (2 equiv with respect to 1 a) and $\mathrm{NaY}$ (1a: NaY in a 1:1 weight ratio).

Successively, solutions of o-aminophenol (1) and m-aminophenol $(\mathbf{1 c})$ in DMC $(0.31 \mathrm{M}, 30 \mathrm{~mL})$ were made to react with $\mathrm{NaY}$ as a catalyst (1),c: $\mathrm{NaY}$ in a $1: 1$ weight ratio). Both $\mathbf{1 b}$ and $\mathbf{1 c}$ were sufficiently soluble in DMC so that a cosolvent was not required. For a comparison, the reaction of $\mathbf{1 b}$ was also run with an acid catalyst ( $\mathrm{p}-\mathrm{CH}_{3} \mathrm{C}_{6} \mathrm{H}_{4} \mathrm{SO}_{3} \mathrm{H}, 2$ equiv with respect to $\mathbf{1 b}$ ).

Results are reported in Table 1.

In the presence of $\mathrm{K}_{2} \mathrm{CO}_{3}$, the reaction of $\mathbf{l a}$ is not selective: for example, at a conversion of $77 \%$, a variety of products of $\mathrm{N}$ - and O-methylation as well as of $\mathrm{N}$-methoxy carbonylation are observed (entry 3). Even at very low conversions ( $2 \%)$, both $\mathrm{N}$ - and O-methyla-

(8) (a) Kalgutkar, A. S.; Kozak, K. R.; Crews, B. C.; Hochgesang, G. C., J r.; Marnett, L. J. J . Med. Chem. 1998, 41, 4800. (b) Black, T. H. Org. Prep. Proced. Int. 1989, 21, 179. (c) Yun, H. S. Chem. Abstr. 1974, 83, 42952.

(9) (a) Ehrlich, J . J . Am. Chem. Soc. 1948, 70, 2286. (b) Paucescu, S. G. V.; Toth, L.; Munteanu, E. G.; Badea, M.; Kurt, S. Patent Appl. RO 80-101931 (1980, 08/08); Chem. Abstr. 100, 120672.

(10) Sakurai, T.; Yamada, S.; I noue, H. Bull. Chem. Soc. J pn. 1986, 59, 2666.

(11) Guo, Z.; Ramirez, J .; Li, J .; Wang, P. G. J . Am. Chem. Soc. 1998, 120, 3726.

(12) J enner, G.; Taleb, A. B. J . Mol. Catal. 1992, 77, 247.

(13) Due to the poor solubility of 1a in DMC, the use of a cosolvent was necessary. F or any given cosolvent, a minumum vol ume was used to obtain the complete solubilization of the substrate at room temperature (see Table 1).

\section{SCHEME 2. Mono-N-methylation of p-Aminophenol}

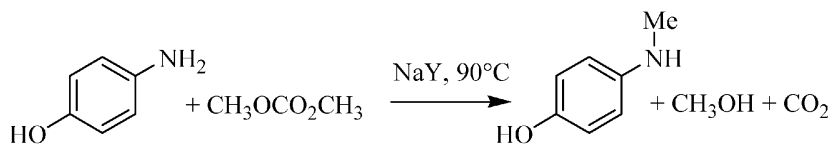

tion of $\mathbf{l a}$ take place simultaneously (entries 1 and 2). This behavior reflects known aspects of the chemistry of DMC: DMC, in fact, is reported as an alkylating agent of phenols, ${ }^{14}$ and under basic catalysis, it exhibits a double reactivity with anilines yiel ding both $\mathrm{N}$-methylanilines and urethanes $\left[\mathrm{ArN}(\mathrm{R}) \mathrm{CO}_{2} \mathrm{Me}, \mathrm{R}=\mathrm{H}, \mathrm{Me}\right] .6,15$

By contrast, in the presence of an amphoteric catalyst such as the NaY zeolite, ${ }^{16}$ DMC turns out to be an excellent chemosel ective reagent: at quantitative conversions, only $\mathrm{N}$-methylation of $\mathbf{l a}$ takes place in a very high mono-N-methyl selectivity (>99\%) and yield $\left[\mathrm{p}-\mathrm{HOC}_{6} \mathrm{H}_{4-}\right.$ $\mathrm{NHMe}(5 \mathrm{a})$ in isolated yield of 91\%] (entries 4 and 5) (Scheme 2).

The nature of the cosolvent is critical for the reaction: glycol-derived dimethyl ethers such as triglyme and DME give the best results (entries 4 and 5), ${ }^{17}$ while the methylation is hindered when carried out in DMF and MeCN (entry 6). This strong inhibiting effect can be ascribed to a competitive adsorption of the polar cosolvent and the substrate for the catalytic cages of the zeolite. $6 c, 18$

The data of Table 1 discl ose a further relevant aspect. As described by us and by others, ,31,15,17 DMC-mediated

(14) (a) Lissel, M.; Schmidt, S.; Neumann, B. Synthesis 1986, 382. (b) Tundo, P.; Selva, M. Chemtech 1995, 25, 31. (c) Bomben, A.; Selva, M.; Tundo, P.; Valli, L. Ind. Eng. Chem. Res. 1999, 38, 2075. (d) Trotta, F.; Tundo, P.; Moraglio, G. J . Org. Chem. 1987, 52, 1300.

(15) Trotta, F.; Tundo, P.; Moraglio, G. J . Org. Chem. 1987, 52, 1300.

(16) Barthomeuf, D. J . Phys. Chem. 1984, 88, 42. The basicity of the solid comes from the basic oxygen atoms of its framework, while Lewis acidity is due to alkaline metal cations.

(17) Triglyme and diglyme have been already reported by us in the alkylation of both phenols and amines with dialkyl carbonates. Perosa, A.; Selva, M.; Tundo, P.; Zordan, F. Synlett 2000, 1, 272-274, and ref $6 \mathrm{~b}$.

(18) (a) Espeel, P. H. J .; Vercruysse, K. A.; Debaerdemaker, M.; J acobs, P. A. Stud. Surf. Sci. Catal. 1994, 84, 1457. (b) J ayat, F.; Sabater Picot, M. J .; Guisnet, M. Catal. Lett. 1996, 41, 181. 
TABLE 2. Mono-N-methylation of p- and o-Aminobenzyl Alcohols (2a,b), p- and o-Aminobenzoic Acids (3a,b), and p- and o-Aminobenzamides $(4 a, b)$ with DMC and NaY as Catalyst

\begin{tabular}{|c|c|c|c|c|c|c|c|c|}
\hline \multirow[b]{2}{*}{ entry } & \multirow[b]{2}{*}{ substrate $(\mathrm{M})^{\mathrm{a}}$} & \multirow[b]{2}{*}{$\mathrm{T},{ }^{\circ} \mathrm{C}$} & \multirow[b]{2}{*}{$t, h$} & \multirow[b]{2}{*}{$\%$ conv } & \multirow[b]{2}{*}{$\% \mathrm{~S}_{M / D^{b}}$} & \multicolumn{3}{|c|}{ products } \\
\hline & & & & & & & $\%$, by GC & $\%$ isolated yield \\
\hline 1 & $\mathbf{2 a}(0.32)$ & 90 & 8 & 90 & 94 & $(\mathrm{p}-\mathrm{HO}) \mathrm{CH}_{2} \mathrm{C}_{6} \mathrm{H}_{4} \mathrm{NHMe}(\mathbf{6 a})$ & 85 & 77 \\
\hline 2 & $\mathbf{2 b}(0.32)$ & 90 & 12 & 99 & 99 & $(\mathrm{o}-\mathrm{HO}) \mathrm{CH}_{2} \mathrm{C}_{6} \mathrm{H}_{4} \mathrm{NHMe}(\mathbf{6 b})$ & 98 & 92 \\
\hline 3 & $3 a(0.12)$ & 130 & 9 & 100 & 90 & $\left(p-\mathrm{HO}_{2} \mathrm{C}\right) \mathrm{C}_{6} \mathrm{H}_{4} \mathrm{NHMe}(\mathbf{7 a})$ & $90^{c}$ & 74 \\
\hline 4 & $\mathbf{3 b}(0.12)$ & 90 & 8 & - & & - & & \\
\hline 5 & $\mathbf{3 b}(0.12)$ & 150 & 5 & 95 & 95 & $\left(\mathrm{o}-\mathrm{HO}_{2} \mathrm{C}\right) \mathrm{C}_{6} \mathrm{H}_{4} \mathrm{NHMe}(\mathbf{7 b})$ & 90 & 83 \\
\hline 6 & $4 \mathbf{a}(0.15)$ & 90 & 24 & 96 & 93 & $\left(\mathrm{p}-\mathrm{H}_{2} \mathrm{NOC}\right) \mathrm{C}_{6} \mathrm{H}_{4} \mathrm{NHMe}(\mathbf{8 a})$ & 89 & 86 \\
\hline 7 & $\mathbf{4 b}(0.32)$ & 90 & 22 & 100 & 94 & $\left(\mathrm{o}-\mathrm{H}_{2} \mathrm{NOC}\right) \mathrm{C}_{6} \mathrm{H}_{4} \mathrm{NHMe}(\mathbf{8 b})$ & 94 & 91 \\
\hline
\end{tabular}

a In parentheses, the molar concentration of the solution of the substrate in DMC is reported. ${ }^{b} \mathrm{~S}_{\mathrm{M} / \mathrm{D}}$ was the selectivity of mono- $\mathrm{N}$ methyl to $\mathrm{N}, \mathrm{N}$-dimethyl derivative expressed as the ratio $\{[\mathrm{ArNHMe}] /([\mathrm{ArNHMe}]+[\mathrm{ArNMe}])\} \times 100 .{ }^{c} \mathrm{The} \mathrm{product}\left(\mathrm{p}-\mathrm{HO}_{2} \mathrm{C}\right) \mathrm{CH}_{2} \mathrm{C}_{6} \mathrm{H}_{4} \mathrm{NHMe}$ could not be analyzed by GC; the reported percentage was calculated from the ${ }^{1} \mathrm{H}$ NMR spectrum.

methylation processes usually take place at high temperatures $\left(120-220^{\circ} \mathrm{C}\right)$. This is also manifest in the reaction of la carried out with $\mathrm{K}_{2} \mathrm{CO}_{3}$ (entries 1-3). However, in the presence of $\mathrm{NaY}$, the reaction of $\mathbf{l a}$ proceeds smoothly at the boiling point of DMC $\left(90^{\circ} \mathrm{C}\right)$. The $\mathrm{OH}$-substituent may account for this results with two effects on the reactant amine: (i) the enhancement of nucleophilicity and (ii) the easier diffusion/adsorption through the polar channel and cages of the catalyst. It should be noted that low-temperature methylations with DMC have been recently reported in only a few instances and they require activation with the use of very strong bases (DBU) or microwave irradiation. ${ }^{19}$

Analogous results in terms of chemo- and mono-Nmethyl-selectivity are obtained in the $\mathrm{NaY}$-catalyzed reaction of o- and m-aminophenols with $\mathrm{DMC}$ : at $90^{\circ} \mathrm{C}$, compounds $\mathbf{I b}$ and $\mathbf{I c}$ give the corresponding mono-Nmethyl derivatives $\left[\mathrm{XC}_{6} \mathrm{H}_{4} \mathrm{NHMe}, \mathrm{X}=\mathrm{O}-\mathrm{OH}(\mathbf{5 b}), \mathrm{m}-\mathrm{OH}\right.$ (5c)] in very high isolated yields (5b, 99\%; 5c, 89\%) and without any concurrent O-methylation or methoxycarbonylation reactions (entries 7 and 9). On the contrary, the use of an acidic catalyst ( $\mathrm{p}-\mathrm{TsOH})$ strongly lowers the overall reaction selectivity (entry 8 ). ${ }^{20}$

Finally, two preliminary experiments were run to assay the catalytic activity of $\mathrm{NaY}$ : solutions of compounds $\mathbf{1 b}$ and $\mathbf{1 c}$ in DMC $(0.31 \mathrm{M}, 30 \mathrm{~mL})$ were made to react in the presence of a lower amount of the zeolite (1: $\mathrm{NaY}=10$ weight ratio). As expected, both reactions were slower, but isolated yields of $\mathbf{5 b}$ and $\mathbf{5 c}$ were still satisfactorily: $93 \%$ and $92 \%$ after 38 and $42 \mathrm{~h}$, respectively.

Aminobenzyl Alcohols (2), Aminobenzoic Acids (3), and Aminobenzamides (4). The direct methylation of compounds 2-4 with $\mathrm{Mel}$ or $\mathrm{Me}_{2} \mathrm{SO}_{4}{ }^{21}$ as well as the reductive methylation, ${ }^{22}$ affords mainly or exclusively $\mathrm{N}, \mathrm{N}$-dimethyl derivatives, while indirect methods via

(19) (a) Shieh, W.-C.; Dell, S.; Repic, O. Org. Lett. 2001, 3, 4279. (b) Shieh, W.-C.; Dell, S.; Repic, O. J . Org. Chem. 2002, 67, 2188.

(20) In the reaction of anilines with organic carbonates, activation by acidic organic catalysts has been al ready proposed for the synthesis of carbamates. Aresta, M.; Berloco, C.; Quaranta, E. Tetrahedron 1995, $51,8073$.

(21) (a) Lu, B. Pat. Appl. CN 99-112785, Chem Abstr. 2000, 133, 163940. (b) Wang, C. L. J. PCT Int. Appl. WO 91-US193, Chem. Abstr 1991, 115, 280027. (c) Wen, S.; Zhu, N. Huaxue Shiji 1990, 12, 243; Chem. Abstr. 1991, 114, 81171.

(22) (a) J ung, Y. J .; Bae, J. W.; Yoon, C.-O. M.; Byung, W.; Yoon, C. M. Synth. Commun. 2001, 31, 3417. (b) Nishimura, T.; Takeda, F.; Wada, M.; Kanamura, Y.J pn. Pat. Appl. J P 98-273619; Chem. Abstr. 2000, 132, 250975.
$\mathrm{N}$-acyl protection of amine groups give moderate yields of mono-N-methyl products. ${ }^{23}$

Under the conditions previously described for $\mathbf{1 b}, \mathbf{c}$ (Table 1, entries 7 and 9), solutions of p- and o-aminobenzyl al cohols and o-ami nobenzamide ( $\mathbf{2} \mathbf{a}, \mathbf{b}$ and $\mathbf{4} \mathbf{b})$ in DMC $(0.32 \mathrm{M}, 30 \mathrm{~mL})$ were made to react at $90^{\circ} \mathrm{C}$, while for $\mathrm{p}$-aminobenzamide $\mathbf{4 a}$ and $\mathrm{o}$ - and $\mathrm{p}$-aminobenzoic acids (3a and $\mathbf{3 b}$ )-which were less soluble in DMC with respect to compounds $\mathbf{2} \mathbf{a}, \mathbf{b}$ and $\mathbf{4} \mathbf{b} \mathbf{-}-$ more dilute solutions were used: experiments were run with $0.15 \mathrm{M}$ $(50 \mathrm{~mL})$ solution of $\mathbf{4 a}$ and $0.12 \mathrm{M}(30 \mathrm{~mL})$ solution of 3a,b in DMC, respectively. Moreover, reactions of compounds 3 were carried out at a higher temperature (130$150^{\circ} \mathrm{C}$ ). In all cases, the weight ratio $\mathrm{NaY}$ /substrate was of 1 .

Results are reported in Table 2.

It should be first noted that under alkaline conditions, dimethyl carbonate readily reacts with primary alcohols, especially benzyl alcohols, and carboxylic acids to yield transesterification and esterification products, respectively $\left(\mathrm{ArCH}_{2} \mathrm{OCO}_{2} \mathrm{Me}\right.$ and $\left.\mathrm{RCO}_{2} \mathrm{Me}\right) \cdot{ }^{19,24,25} \mathrm{And}$, although with more difficulty, carboxamides gives $\mathrm{N}$-methylamides $^{26}$ (Scheme 3, path a).

The use of $\mathrm{NaY}$ as a catalyst completely modifies this scenario. Table 2 shows that reactions of DMC with substrates 2-4 are highly chemoselective: only the amine function undergoes methylation, while $\mathrm{OH}, \mathrm{CO}_{2} \mathrm{H}$, and $\mathrm{CONH}_{2}$ groups do not react at all. Particularly, in all cases the corresponding mono- $\mathrm{N}$-methyl derivatives $\left[\mathrm{XC}_{6} \mathrm{H}_{4} \mathrm{NHMe} ; \mathrm{X}=\mathrm{CH}_{2} \mathrm{OH}(6), \mathrm{CO}_{2} \mathrm{H}(7)\right.$, and $\mathrm{CONH}_{2}$ (8)] are obtained with a selectivity of $90-99 \%$ and isolated yields of $74-92 \%$ (Scheme 3, path b).

Table 2 al so indicates that aminobenzyl alcohols $\mathbf{2}$ are the more active substrates (entries 1 and 2), while aminobenzamides 4, which still react at $90{ }^{\circ} \mathrm{C}$, require longer reaction times (entries 6 and 7). Aminobenzoic acids $\mathbf{3}$ yield mono- $\mathrm{N}$-methyl derivatives only at temperature over $130^{\circ} \mathrm{C}$ (entries 3-5). Although the $\mathrm{N}$-alkylation of anilines over $\mathrm{NaY}$ is expected to occur within the zeolitic cages, ${ }^{6,18,27,28}$ this reactivity scale is likely due

(23) Skupinski, W.; Pichnej, L.; Pakula, R.; J ahn-Andrychowska, W. Trojanowska, Z.; Butkiewicz, K. Arch. Pharm. (Weinheim, Ger.) 1986, $319,862$.

(24) (a) Tundo, P. In Continuous Flow Methods in Organic Synthesis Horwood, E. Pub.: Chichester (UK), 1991. (b) Perosa, A.; Selva, M.; Tundo, P.; Zordan, F. Synlett 2000, 1, 272-274.

(25) (a) Loosen, P.; Tundo, P.; Selva, M. US Patent 5,278,333, 1994.

(b) Shieh, W.; Dell, S.; Repic, O. Tetrahedron Lett. 2002, 43, 5607.

(26) Ben Taleb, A.; J enner, G. J . Mol. Catal. 1993, 84, L131. 


\section{SCHEME 3}

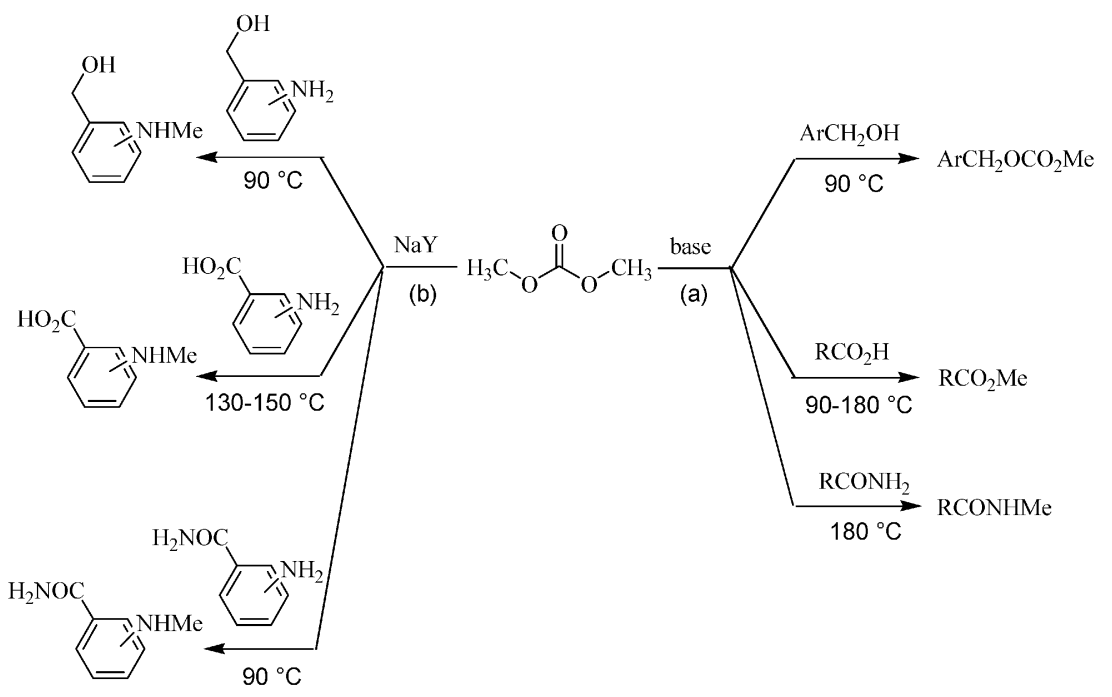

\section{SCHEME 4}

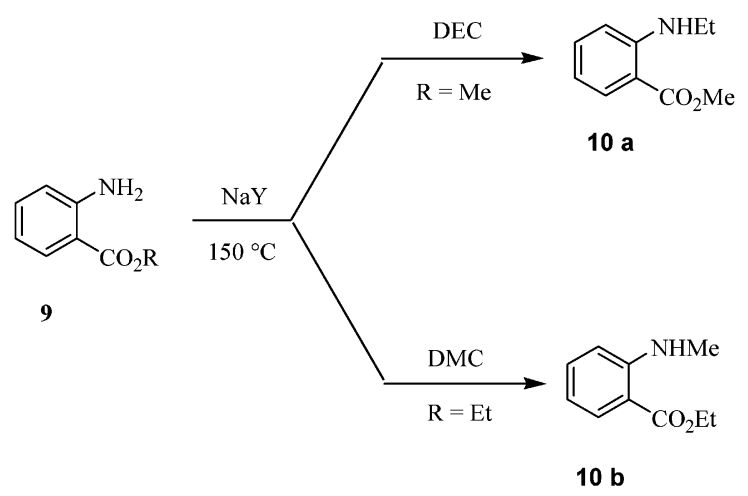

to the el ectronic effects of substituents, ${ }^{29}$ rather than to their steric requisites.

A high chemoselectivity was also evident in the $\mathrm{NaY}$ catalyzed reactions of methyl and ethyl anthranilates (compounds $\mathbf{9 a}$ and $\mathbf{9 b}$ ) with diethyl carbonate (DEC) and DMC, respectively (Scheme 4).

Both reactions yielded exclusively the corresponding mono- $\mathrm{N}$-alkylated derivatives $(\mathbf{1 0 a}, \mathbf{b})$. Although the alkylation of the esters 9 was slow even at $150^{\circ} \mathrm{C}$ (after $8 \mathrm{~h}$, conversions of $\mathbf{9 a}$ and $\mathbf{9 b}$ were of $25 \%$ and $65 \%$, respectively), no trace of the transesterification products [(o$\left.\mathrm{MeO}_{2} \mathrm{C}\right) \mathrm{C}_{6} \mathrm{H}_{4} \mathrm{NHMe}$ or (o-EtO $\left.{ }_{2} \mathrm{C}\right) \mathrm{C}_{6} \mathrm{H}_{4} \mathrm{NHEt}$ ] was observed.

\section{Conclusions}

A powerful method is described for a straightforward and selective $\mathrm{N}$-methylation of anilines bearing a variety of functional groups which, though susceptible to undergo themselves methylation reactions, are kept untouched. This fine control of the chemoselectivity is made possible

(27) (a) Fu, Z.-H.; Ono, Y. Catal. Lett. 1993, 22, 277. (b) Hari Prasad Rao, P. R.; Massiani, P.; Barthomeuf, D. Catal. Lett. 1995, 31, 115. (28) Czjiek, M.; Vogt, T.; Fuess, H. Zeolites 1991, 11, 832.

(29) The $\mathrm{OH}$ and $\mathrm{CH}_{2} \mathrm{OH}$ groups have electron-donating effects on the aryl ring. For the other substituents, the electron-withdrawing effect follows the order $\mathrm{CO}_{2} \mathrm{H}>\mathrm{CONH}_{2}$. (March, J. In Advanced Organic Chemistry, 4th ed.; Wiley: New York, 1991; pp 681-685). Accordingly, the nucleophilicity order of the tested amines should be $\mathbf{1}>\mathbf{2}>\mathbf{3}>\mathbf{4}$ by the use of $\mathrm{NaY}$ zeolite as a catalyst with amphoteric properties able to promote exclusively the reactivity of the amine function. The features of DMC as a methylating agent additionally increase the synthetic potential of the procedure, since only mono- $\mathrm{N}$-methyl anilines are obtained with selectivity up to $99 \%$.

Although the solubility of compounds 1-4 in DMC and, more generally, reaction conditions need a case-by-case optimization, other advantageous aspects are the simplicity of the procedure and its intrinsic environmentally benign character as nontoxic methylating agent/catalyst are used, no wastes are generated, and derivatization reactions with protecting groups are avoided. ${ }^{30}$

\section{Experimental Section}

All compounds used were ACS grade and were employed without further purification. The zeolite $\mathrm{NaY}$ was dried before each reaction by heating at $70^{\circ} \mathrm{C}$, under vacuum overnight. ${ }^{1} \mathrm{H}$ NMR spectra were recorded on a $300 \mathrm{MHz}$ spectrometer. GLC and GC/MS (70 eV) analyses were run using CPSil24CB and HP5 capillary columns (30 m), respectively.

Reaction of Compounds 1, 2, and 4 with DMC. General Procedure. A two-necked, jacketed, $100 \mathrm{~mL}$ round-bottomed flask fitted with a reflux condenser capped with a $\mathrm{CaCl}_{2}$ tube, an adapter for the withdrawal of samples, and a magnetic bar was loaded with the titled compounds and DMC according to the following concentrations: (i) $0.31 \mathrm{M}$ solutions $(30 \mathrm{~mL}$ ) of o- and m-aminophenols (1),c, $1.0 \mathrm{~g}, 9.2 \mathrm{mmol}$ ), (ii) $0.32 \mathrm{M}$ solutions ( $30 \mathrm{~mL}$ ) of o- and p-aminobenzyl alcohols (2a,b: 1.18 g, $9.6 \mathrm{mmol}$ ), (iii) $0.32 \mathrm{M}$ solution ( $30 \mathrm{~mL}$ ) of o-aminobenzamide (4b: $1.30 \mathrm{~g}, 0.0096 \mathrm{mmol}$ ), (iv); $0.15 \mathrm{M}$ solution $(50 \mathrm{~mL}$ ) of p-aminobenzamide (4a: $1.0 \mathrm{~g}, 0.0075 \mathrm{mmol}$ ). In the case of p-aminophenol 1a, solutions of 1a (1.0 g, $9.2 \mathrm{mmol}), \mathrm{DMC}(10$ $\mathrm{mL}, 0.12 \mathrm{~mol}$ ), and a cosolvent such as triglyme ( $35 \mathrm{~mL})$, DMF (15 mL), 1,2-dimethoxyethane (DME, $35 \mathrm{~mL}$ ), or MeCN (35 $\mathrm{mL}$ ) were used; the cosolvent was added in the minimun volume to allow a complete solubilization of the substrate at room temperature. If not otherwise indicated, the catalyst $\mathrm{NaY}$ was then added in a weight ratio of 1 with respect to the reactant amines.

The flask was heated at the reflux temperature of DMC ( 90 $\left.{ }^{\circ} \mathrm{C}\right)$, while the mixture was vigorously stirred. At intervals, samples $(0.1 \mathrm{~mL})$ were withdrawn and were analyzed by GC and GC/MS.

(30) Anastas, P. T.; Warner, J . C. In Green Chemistry, Theory and Practice; Oxford University Press: Oxford, 1998. 
In the case of $\mathbf{1 a}$, when DME and $\mathrm{MeCN}$ were used as cosolvents, reactions were run at 86 and $81{ }^{\circ} \mathrm{C}$, respectively.

Once the reaction was completed, the pale yellow suspension was filtered and the solid catalyst was thoroughly washed with $\mathrm{MeOH}(15 \mathrm{~mL})$. After rotary evaporation, the mono-N-methylated products $\mathrm{XC}_{6} \mathrm{H}_{4} \mathrm{NHMe}, \mathrm{X}=\mathrm{o}-, \mathrm{m}-$, and $\mathrm{p}-\mathrm{OH}(\mathbf{5} \mathbf{a}, \mathbf{5 b}$, and $5 \mathbf{c}$ ); $0-\mathrm{CH}_{2} \mathrm{OH}(\mathbf{6 b})$; and $\mathrm{o}-\mathrm{CONH}_{2}(\mathbf{8 b})$ were pure (94$99 \%$ by GC) and characterized as such. Compounds $\mathbf{6 a}$ (p-HOCH${ }_{2} \mathrm{C}_{6} \mathrm{H}_{4} \mathrm{NHMe}$ ) and $\mathbf{8 a}\left(\mathrm{p}-\mathrm{H}_{2} \mathrm{NCOC}_{6} \mathrm{H}_{4} \mathrm{NHMe}\right)$ were purified by flash chromatography (eluant: AcOEt/petroleum ether, $1: 4 \mathrm{v} / \mathrm{v}$ ).

p-Aminophenol 1a was also made to react with DMC in the presence of $\mathrm{K}_{2} \mathrm{CO}_{3}$ as a catalyst. Since no reaction took place at the reflux temperature $\left(90^{\circ} \mathrm{C}\right)$, experiments were run by loading an autoclave ( $150 \mathrm{~mL}$ of internal volume) with a mixture of la $(1.0 \mathrm{~g}, 9.2 \mathrm{mmol}), \mathrm{K}_{2} \mathrm{CO}_{3}(2.53 \mathrm{~g}, 18.3 \mathrm{mmol})$, DMC $(10 \mathrm{~mL})$, and a cosolvent [triglyme $(35 \mathrm{~mL})$ or DME (35 $\mathrm{mL})$, or DMF $(15 \mathrm{~mL})$ ], which was heated at the desired temperature $\left(125-150{ }^{\circ} \mathrm{C}\right.$; see Table 1 , entries $\left.1-3\right)$ and kept under magnetic stirring. After a time interval (entries 1-3, Table 1), the autoclave was cooled to room temperature and vented. Then, the mixture was analyzed by GC and GC/MS.

Reaction of Compounds 3 with DMC. General Procedure. A stainless steel autoclave ( $150 \mathrm{~mL}$ of internal volume) was charged with a solution of compound $\mathbf{3 a}$ or $\mathbf{3 b}$ in DMC $(0.12 \mathrm{M}, 30 \mathrm{~mL}$ ) and $\mathrm{NaY}$ (3: $\mathrm{NaY}=1$ weight ratio). Before the reaction, air was removed by purging with $\mathrm{N}_{2}$ stream at room temperature. The autoclave was then heated by an oilcirculating jacket at the desired temperature $\left(130-150{ }^{\circ} \mathrm{C}\right)$, while the mixture was kept under magnetic stirring. A thermocouple fixed into the autoclave head maintained the temperature throughout the reaction. Once the reaction was completed, the autoclave was cooled to room temperature, vented, and opened. The workup of the suspension was carried out as described in the procedure above. Both compounds $\mathbf{7 a , b}$ were purified by flash chromatography (eluant: AcOEt/ petroleum ether, $1: 3 \mathrm{v} / \mathrm{v}$ ).

Compound $\mathbf{3 b}$ was also made to react with DMC at $90{ }^{\circ} \mathrm{C}$ following the procedure above-described for amines $\mathbf{1}, \mathbf{2}$, and 4.

All compounds-except for $\mathbf{7 a}$-were characterized by GC/ MS and by ${ }^{1} \mathrm{H}$ NMR. Spectroscopic and physical properties were in agreement with those reported in the literature: $\mathbf{5 a}$, $\mathrm{mp} 80-83^{\circ} \mathrm{C}$ (dark brow solid) (lit. ${ }^{31} \mathrm{mp} 87$ ); 5b, mp 93-95 ${ }^{\circ} \mathrm{C}$ (yellow solid) (lit. ${ }^{31 b, 32} \mathrm{mp} 96-97^{\circ} \mathrm{C}$ ); 5c, brown oil, lit. ${ }^{31 \mathrm{~b}}$ bp $190^{\circ} \mathrm{C} / 40 \mathrm{~mm}$ (solidifies on standing); $6 \mathbf{a}$, yellow solid at 4

(31) (a) Guo, Z.; Ramirez, J .; Li, J .; Wang, P. G. J . Am. Chem. Soc 1998, 120, 3726. (b) Dictionary of Organic Compounds, 5th ed.; Chapman \& Hall: New York, 1982; Vol. 4, p 3727.
${ }^{\circ} \mathrm{C}$, tends to liquefy at room temperature; $\mathbf{6 b}$, yellow oil, lit. ${ }^{33}$ bp $84-86^{\circ} \mathrm{C} / 0.3 \mathrm{~mm} ; \mathbf{7 a}, \mathrm{mp} 151.5-152.5^{\circ} \mathrm{C}$ (white solid) (lit. ${ }^{34}$ $\mathrm{mp}$ 155-157); $\mathbf{7 b}, \mathrm{mp} 170-173^{\circ} \mathrm{C}$ (lit. $\left.{ }^{34 \mathrm{~b}} \mathrm{mp} 178-179{ }^{\circ} \mathrm{C}\right) ; \mathbf{8 a}$, mp $137-139{ }^{\circ} \mathrm{C}$ (white solid) (lit. ${ }^{34 b, 35} \mathrm{mp} 143-145^{\circ} \mathrm{C}$ ); $8 \mathbf{b}$, $\mathrm{mp}$ 159-160.5 ${ }^{\circ} \mathrm{C}$ (white solid) (lit. $34 \mathrm{~b} \mathrm{mp} 162-163{ }^{\circ} \mathrm{C}$ ). Compound 7a was characterized by ${ }^{1} \mathrm{H}$ NMR: its structure was also confirmed by comparison with an authentic commercial sample.

${ }^{1} \mathrm{H}$ NMR and GC/MS spectra of all compounds are available as Supporting Information.

Reaction of Compounds 9 with DMC. General Procedure. Compounds $\mathbf{9 a}$ (methyl anthranilate) and $\mathbf{9 b}$ (ethyl anthranilate) were made to react with DEC (diethyl carbonate) and DMC, respectively. Experiments were carried out in an autoclave at $150{ }^{\circ} \mathrm{C}$, using the above-described procedure for the reaction of compounds 3 . In particular, solutions of $\mathbf{9 a}$ (1.0 $\mathrm{g}, 6.6 \mathrm{mmol})$ in DEC (35 mL, $0.29 \mathrm{~mol})$ and of $\mathbf{9 b}(0.9 \mathrm{~g}, 5.5$ $\mathrm{mmol}$ ) in DMC (35 mL, $0.39 \mathrm{~mol}$ ) were employed. NaY was the catalyst (weight ratio 9: $\mathrm{NaY}=1$ ). After $8 \mathrm{~h}$, conversions of $9 \mathbf{a}$ and $\mathbf{9 b}$ were $25 \%$ and of $65 \%$, respectively, with the formation of the corresponding methyl $\mathrm{N}$-ethylanthranilate [(o$\mathrm{CO}_{2} \mathrm{Me}$ ) $\mathrm{C}_{6} \mathrm{H}_{4} \mathrm{NHEt}: \mathbf{1 0 a},{ }^{36}$ ] and ethyl $\mathrm{N}$-methylanthranilate $\left[\left(\mathrm{o}-\mathrm{CO}_{2} \mathrm{Et}\right) \mathrm{C}_{6} \mathrm{H}_{4} \mathrm{NHMe:} \mathbf{1 0 b}^{37}\right]$ as the sole products. Compounds $\mathbf{1 0} \mathbf{a}, \mathbf{b}$ were not isolated from the reaction mixture: their structure was assigned by GC/MS and the related spectra are available as Supporting Information.

Acknowledgment. MIUR (Italian Ministry of University) and INCA (Interuniversity Consortium Chemistry for the Environment) are gratefully acknowledged for financial support.

Supporting Information Available: ${ }^{1} \mathrm{H}$ NMR and GC/ MS spectra for all mono-N-methylated amines $\mathbf{5 a}-\mathbf{c}, \mathbf{6} \mathbf{a}, \mathbf{b}$, $\mathbf{7 a}, \mathbf{b}, \mathbf{8 a}, \mathbf{b}$. This material is available free of charge via the Internet at http://pubs.acs.org.

J 0034548A

(32) Kalgutkar, A. S.; Kozak, K. R.; Crews, B. C.; Hochgesang, G. C., J r.; Marnett, L.J . J . Med. Chem. 1998, 41, 4800

(33) Hutchins, J. E. C.; Fife, T. H.J . Am. Chem. Soc. 1973, 95, 3786.

(34) (a) Katritzky, A. R.; Rachwal, S.; Rachwal, B. J . Chem. Soc., Perkin Trans. 1, 1987, 805. (b) Dictionary of Organic Compounds, 5th ed.: Chapman \& Hall: New York, 1982; Vol. 4, p 3724

(35) Kadin, S. B. J . Org. Chem. 1973, 38, 1348.

(36) Olofson, R. A.; Vander Meer, R. K.; Hoskin, D. H.; Bernheim, M. Y.; Stournas, S.; Morrison, D. S. J . Org. Chem. 1984, 49, 33673372.

(37) Khanapure, S. P.; Bhawal, B. M.; Biehl, E. R. Tetrahedron Lett. 1990, 31, 2869-2872. 